\title{
Nutritional Status of Tuberculous Children Diagnosed and Treated in an Urban Area in DR Congo
}

\author{
Bafwafwa Ntumba Don Dieu1,2, Kanteng A. Wakamb Gray¹, Mutombo Mulangu Augustin1, \\ Lukamba Mbuli Robert ${ }^{1}$, Tshikamba Erick ${ }^{3}$, Wembonyama Okitotsho Stanislas ${ }^{1}$, \\ Luboya Numbi Oscar ${ }^{1}$
}

${ }^{1}$ Department of Pediatrics, University Clinics of Lubumbashi, University of Lubumbashi, Lubumbashi, DR Congo

${ }^{2}$ Office Health Information, Communication and Research, Provincial Division of the Health, Kasai Oriental, Mbuji-Mayi, DR Congo

${ }^{3}$ Measure Evaluation, Mbuji-Mayi, DR Congo

Email: gkanteng@yahoo.fr

How to cite this paper: Dieu, B.N.D., Gray, K.A.W., Augustin, M.M., Robert, L.M., Erick, T., Stanislas, W.O. and Oscar, L.N. (2017) Nutritional Status of Tuberculous Children Diagnosed and Treated in an Urban Area in DR Congo. Open Access Library Journal, 4: e3557.

https://doi.org/10.4236/oalib.1103557

Received: March 24, 2017

Accepted: May 1, 2017

Published: May 4, 2017

Copyright ( $\odot 2017$ by authors and Open Access Library Inc.

This work is licensed under the Creative Commons Attribution International License (CC BY 4.0).

http://creativecommons.org/licenses/by/4.0/

\begin{abstract}
Introduction: Tuberculosis and malnutrition are major health problems in DR Congo, and children are particularly vulnerable. The objective of this study is to determine the incidence of malnutrition in tuberculous children in DR Congo and to identify the associated factors. Methodology: A cross sectional study was conducted, and concerned 22 Tuberculosis Diagnosis and Treatment Centers (TDTCs). It was carried out over a period from 2013 to 2015 and involved 717 tuberculosis children less than 15 years of age. Nutritional status was assessed on the basis of the values of the Z-score Weight for age (global malnutrition) according to the NCHS curves. Results: Tuberculosis incidence was $8.2 \%$. The prevalence of underweight ( $<-2 \mathrm{z}$-score) is $20.8 \%$, of which $8.4 \%$ is severely malnourished ( $<-3 \mathrm{z}$-score). An age of less than 60 months is significantly associated with poor nutritional status $(\mathrm{OR}=0.3, \mathrm{CI}$ 0.2 - 0.5). TB-HIV co-infection is significantly associated with poor nutritional status ( $\mathrm{OR}=0.4$, CI $0.2-0.6$ ). It was noticed that the outcome is favorable (recovery) in patients with good nutritional status ( $\mathrm{OR}=12$, CI 8.0 - 18.9). Conclusion: Underweight is present in Congolese tuberculosis children. An adequate nutritional policy is needed to improve the prognosis of the disease.
\end{abstract}

\section{Subject Areas \\ Pediatrics}

\section{Keywords}

Tuberculosis, Child, Nutritional Status, DR Congo 


\section{Introduction}

With 2 billion people infected worldwide and 9.4 million newly infected per year, tuberculosis is a major global infectious disease [1]. The Democratic Republic of Congo (DRC) is one of the 22 countries that support more than $80 \%$ of the burden of tuberculosis in the world [2]. Indeed, in the DRC, tuberculosis has a prevalence of 842 cases per 100,000 inhabitants with $84 \%$ of new bacilliferous cases. The DRC occupies the $11^{\text {th }}$ rank of the most affected African countries [1]. This remains a significant cause of mortality and morbidity in low-resources countries.

At least a half million children are infected with tuberculosis each year, and an estimated 70,000 are dying [1]. About $11 \%$ of tuberculosis cases concern children less than 15 years of age [3]. In underdeveloped countries, children account for more than $25 \%$ of the tuberculosis burden, but only between $3 \%$ and $6 \%$ of tuberculosis cases in developed countries [3].

Malnutrition has a high prevalence among children living in countries where tuberculosis is highly endemic and contributes to 2.2 million deaths among children fewer than five years of age [4]. According to the UNICEF 2014 report, $24 \%$ of children in the DRC are moderately or severely underweight; $43 \%$ have moderate or severe stunting and $9 \%$ are wasting [5]. Malnourished children are at greater risk of contracting tuberculosis, and vice versa, tuberculosis is likely to degrade the nutritional status of affected children [6].

We have conducted this study in order to establish the nutritional profile of the tuberculous children in the DRC. To achieve this we have set the following specific objectives: to determine the incidence of malnutrition in tuberculous children in an urban area of DR Congo and to identify factors associated to the nutritional status in these patients.

\section{Material and Methods}

\subsection{Study Context}

This study was conducted in Lubumbashi. It is the economic capital of the DR Congo; it is also the capital of the province of Haut-Katanga. Moreover, it is the second most populous city of the DR Congo. Its population would be around 2 million inhabitants according to the latest estimates, with an area of $747 \mathrm{~km}^{2}$. Its density is 2391 habitants $/ \mathrm{km}^{2}$.

In DR Congo, tuberculosis control is the mission of the National Tuberculosis Control Program (NTP). In order to achieve its various objectives, the NTP recommends an integrated approach to tuberculosis control activities in primary health care structures in line with the strategy for strengthening the health system.

The structure that ensures the diagnosis and treatment of tuberculosis patients is called the Tuberculosis Diagnosis and Treatment Center (TDTC). The TDTC is the functional unit of the NTP. The TDTC is equipped with diagnostic tools (a microscope with immersion lens, rapid diagnostic tests, etc.) endorsed by the 
WHO, and has trained medical personnel. A sample of the sputum smears collected by the TDTCs is also regularly monitored by the higher level according to the national strategy in this area.

Some TDTCs are equipped with XPERT MTB/Rif machines depending on their strategic location and the number of suspected multiresistant (MR) cases surroundings.

Screening and treatment are free. The drug supply and other inputs to tuberculosis control are subsidized.

The data were collected after all of the TDTCs of Lubumbashi, 22 centers.

\subsection{Period and Study Design}

This is a descriptive cross-sectional study, which was conducted from 1st January 2013 to 31st December 2015, a 3 years period.

\subsection{Population of Study}

Our target population is children under 15 years of age, living in Lubumbashi.

\subsection{Sampling}

- Size sample: 8699 tuberculosis cases were collected during the period of our study, including 717 children having constituted our sample.

- Sample type: we proceeded to a convenience sampling, according with inclusion criteria below.

- Inclusion criteria: we have included children from 0 to 14 years diagnosed and treated for tuberculosis. The diagnosis of tuberculosis was based on NTP guide criteria in conformity with WHO recommendations for TB in children. The following elements were researched: a significant Keith Edwards score [7] with at least one paraclinic criterion suggestive of tuberculosis: a positive Ziehl test, an evocative X-ray, a positive intradermoreaction, a positive serology or a positive culture of Koch Bacillus.

- Non-inclusion criteria: patients with incomplete study parameters were excluded from the study.

\subsection{Study Parameters}

The following socio-demographic parameters were collected for each child: age in months, sex and commune of provenance.

Apart from weight, elements of anamnesis and clinical examination were collected, the HIV status and the evolution especially.

\subsection{Data Collection}

We have carried out the technique of documentary review to carry out the collection of our data. It was based on the follow-up records and the registers of the patients as drawn up in the different TDTCs.

For the evaluation of nutritional status, the usual material used to perform anthropometry was used, namely a Salter ${ }^{\circledR}$ scale with accuracy to $100 \mathrm{mg}$ for 
weight gain.

HIV serology was made with a rapid screening test (Determine ${ }^{\circledast}$ ) confirmed by a $2^{\text {nd }}$ discriminative test $\left(\right.$ Unigold $\left.^{\circledR}\right)$.

\subsection{Processing Data}

- The determination of the nutritional status's is made based on the following indicators: weight and age, allowing the calculation of Z-score Weight for Age to indicate global malnutrition.

The calculation of Z-score is based on the following formula:

$\mathrm{Z}$-score $=$ (Measured value - Average value in the reference population) $/$ Standard deviation of the reference population.

In this study, the Z-score calculation used the ENA software (Emergency $\mathrm{Nu}$ trition Assessment) 2007 Version, based on NCHS curves. Nutritional status was classified as follows: normal nutritional status (Z-score greater than or equal to -1.00 ), mild malnutrition (Z-score between -2.00 to -1.01 ), moderate malnutrition (Z-score between -3.00 to -2.01$)$ and severe malnutrition (Z-score less than $-3.00)[8]$.

- The encoding of data was made using Excel 2013 software on Windows 2013.

- The processing of data was made by using Epi-Info 7 (2013), to generate statistical tests. So was calculated the mean with standard deviation, and the median. When association is performed between two or more parameters, Odds-ratio was generated, with a $95 \%$ confidence interval. The p-value signification level is $<5 \%$.

\subsection{Ethical Considerations}

Respect for the anonymity of patients was respected. The administrative authorizations required for the completion of the data collection were duly obtained.

\section{Results}

The frequency of tuberculosis in children compared to the total number of patients followed for tuberculosis in Lubumbashi is $717 / 8699$ cases, a frequency of $8.2 \%$.

Figure 1 shows that the distribution curve of the study population is deviated to the left of the reference Gauss curve, suggesting that part of the population is affected by the weight deficit.

The prevalence of underweight (<-2 z-score) was 20.8\% (CI 17.8 - 23.8) (n = $149)$. It is more frequent for boys with $23.6 \%$ (CI $19.3-27.9)(n=89)$ than girls with $17.6 \%$ (CI 13.6 - 21.7) $(\mathrm{n}=60)$

The prevalence of moderate malnutrition ( $<-2 \mathrm{z}$-score and $\geq-3 \mathrm{z}$-score) was $12.4 \%(10.0$ - $14.8 \mathrm{CI})(\mathrm{n}=89)$. It is more common for boys with $13.3 \%(9.8-$ $16.7 \mathrm{CI})(\mathrm{n}=50)$ than girls, $11.5 \%(8.1-14.9 \mathrm{CI})(\mathrm{n}=39)$.

The prevalence of severe malnutrition (<-3 z-score) was $8.4 \%(6.3-10.4 \mathrm{CI})$ $(n=60)$. It is more common for boys with $10.3 \%(7.3-13.4 \mathrm{CI})(n=60)$ than 


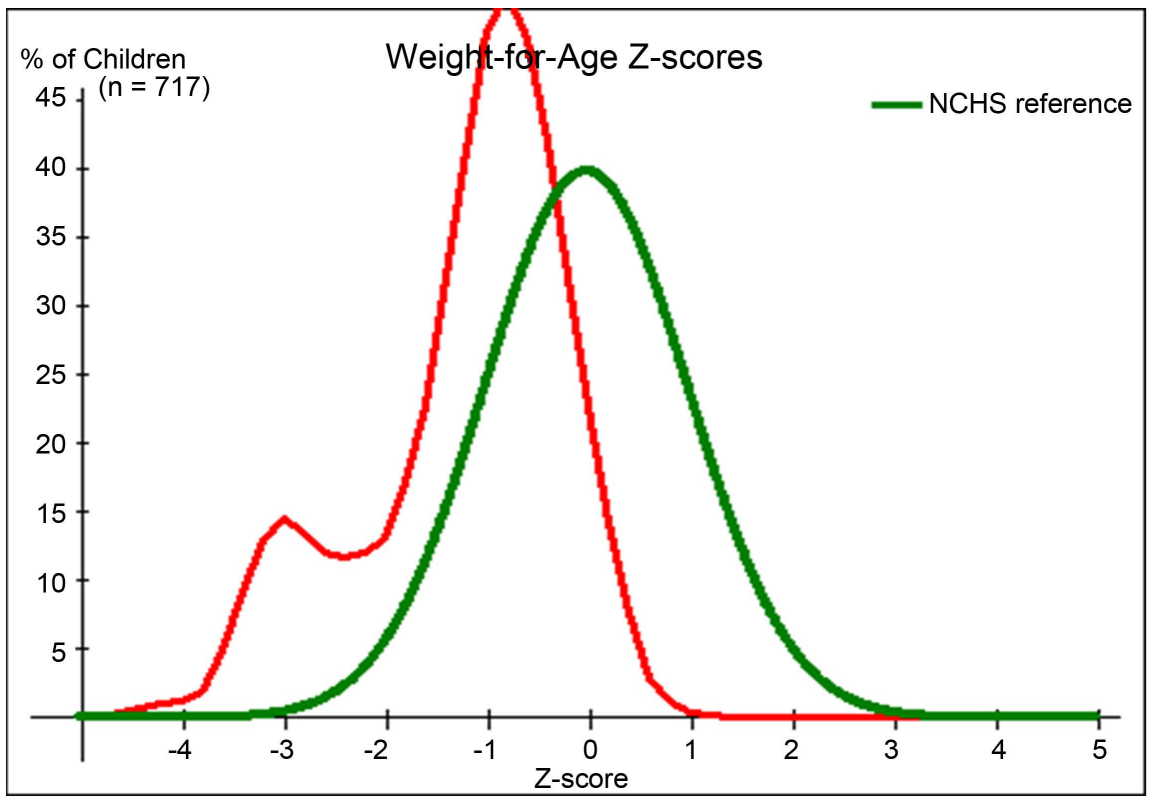

Figure 1. Distribution of cases according to the Weight-for-Age Z-score.

Table 1. Distribution of cases according to the socio-demographic parameters of patients.

\begin{tabular}{|c|c|c|c|c|}
\hline & Settings & Number of cases & Percentage & Statistical parameters \\
\hline \multirow{3}{*}{ Age } & $<60$ months & 163 & $22.7 \%$ & Mean $=100.2$ months \\
\hline & & & & Extremes $=6$ and 168 months \\
\hline & $>60$ months & 554 & $77.3 \%$ & $\begin{array}{c}\text { Median }=108 \text { months; SD }=47.6 \\
\text { months }\end{array}$ \\
\hline \multirow{2}{*}{ Sex } & Female (F) & 341 & $47.5 \%$ & Sex-ratio $\mathrm{F} / \mathrm{M}=0.9$ \\
\hline & Male (M) & 376 & $52.5 \%$ & \\
\hline \multirow[b]{2}{*}{ Origin } & Lubumbashi & 656 & $91.5 \%$ & \\
\hline & $\begin{array}{l}\text { Out of Lubumba- } \\
\text { shi }\end{array}$ & 61 & $8.5 \%$ & \\
\hline
\end{tabular}

girls with 6.2\% (3.6 - 8.7 CI) $(\mathrm{n}=21)($ Table 2$)$.

Table 3 reveals some significant associations with nutritional status. First, there is $30 \%$ of chance for a tuberculous child under 60 months of age to have a poor nutritional status. Then there is a greater chance for tuberculous patients HIV positive to have poor nutritional status ( $40 \%$ more likely) than for HIV negative patients. Finally, there is a 12 -fold increase in the chance of recovery in patients with better nutritional status than in those in poor nutritional status.

\section{Discussion}

\subsection{Limitation of Study}

It should be recognized that the nutritional status assessment was not extended to the Weigh- f-height and height-for-age Z-scores, which could have highlighted acute malnutrition and chronic malnutrition, respectively. This is related to the fact that the examination of the patient, often summarized in several TDCTs, forgets to mention the size. The Z-score Weight-for-Age used here is 
Table 2. Distribution of cases according to the Z-score PPA.

\begin{tabular}{ccc}
\hline Weight-for-Age Z-score & Cases & Percentage \\
\hline$>-1$ & 365 & $50.9 \%$ \\
-1 to 2 & 203 & $28.3 \%$ \\
-2 to -3 & 89 & $12.4 \%$ \\
$<-3$ & 60 & $8.4 \%$ \\
\hline
\end{tabular}

Table 3. Factors associated with nutritional status.

\begin{tabular}{|c|c|c|c|c|c|c|}
\hline \multicolumn{2}{|c|}{ Parameters } & $>-1 \mathrm{Z}$-score WFA & \multicolumn{2}{|c|}{$\leq-1 \mathrm{Z}$-score WFA P-Value } & \multirow{2}{*}{$\begin{array}{l}\text { OR } \\
0.3\end{array}$} & \multirow{2}{*}{$\begin{array}{c}\text { CI } \\
0.2 \text { to } 0.5\end{array}$} \\
\hline & $<60$ months & 52 & 111 & 0.0000 & & \\
\hline & $\geq 60$ months & 313 & 241 & & & \\
\hline \multirow{2}{*}{ Provenance } & Out of Lubumbashi & 26 & 35 & 0.1760 & 0.6 & 0.4 to 1.1 \\
\hline & Lubumbashi & 339 & 317 & & & \\
\hline TB-HIV & HIV+ & 48 & 91 & 0.0000 & 0.4 & 0.2 to 0.6 \\
\hline Co-infection & HIV- & 317 & 261 & & & \\
\hline \multirow[b]{2}{*}{ Issue } & Recovery & 335 & 167 & 0.0000 & 12 & $8.0-18.9$ \\
\hline & $\begin{array}{c}\text { Death or therapeu- } \\
\text { tic failure }\end{array}$ & 30 & 185 & & & \\
\hline
\end{tabular}

the reflection of the underweight alone, hence global malnutrition.

\subsection{Description of the Population}

Our study population constitutes $8.2 \%$ of the total tuberculosis population monitored in Lubumbashi. This is a high frequency, but it falls within the thresholds of the figures presented in other studies in sub-Saharan Africa, between $6 \%$ and $39 \%$. These figures reflect the precarious living conditions of the population, but probably also the result of the high rate of HIV infection, including tuberculosis can be a corollary [9] [10] [11] [12].

In comparison, we know that in developed countries tuberculosis is essentially an adult pathology; an 8-year Taiwan study that found $0.85 \%$ of tuberculosis cases in children compared to cases diagnosed in adults [13].

In terms of socio-demographic parameters, most of the patients came from the city of Lubumbashi (91.4\%). There is no significant difference in the distribution of cases in relation to sex, with the sex ratio being 0.9 .

\subsection{General Nutritional Status of Patients}

According to the EDS II report in the DRC, about $23 \%$ of children under five are underweight and $7 \%$ in severe form. These proportions are significantly higher than those expected in a healthy and well-nourished population $(2.3 \%$ and $0.1 \%$, respectively) [14]. In our study, the prevalence of underweight ( $<-2 \mathrm{z}$-score) was $20.8 \%$, of which $8.4 \%$ was severely malnourished ( $<-3 \mathrm{z}$-score). This is supplementary to the nutritional status of the general Congolese population. 
Nevertheless, there is evidence of greater risk in patients with a precarious nutritional status to develop tuberculosis. One study highlights the role of vitamin $\mathrm{D}$ receptors, influencing the immune response to respiratory infections in malnourished children, particularly in tuberculosis. This also suggests the wider need to supplement these tuberculous children with micronutrients and macronutrients [4] [15]. However, this option is neither explicit nor systematic in the national program for the management of tuberculosis patients in DR Congo.

\subsection{Factors Associated with Nutritional Status}

The first factor highlighted as significantly associated with the nutritional status of malnourished is age. Age less than 60 months is associated with a significantly more deleterious nutritional status than age greater than 60 months. In DR Congo, the risk of developing underweight is increased by 5 years $(21 \%$ of the population at this age) and is already present even in infants younger than 6 months (10\% of infants ) [14]. This underlines the urgent need to integrate nutritional management into anti-tuberculosis treatment in children in general.

Second, it has been shown that poor nutritional status is significantly associated with positive HIV serology. HIV leads to immunodeficiency, on which tuberculosis finds a propitious ground for development. At the same time, HIV immunodeficiency is itself responsible for a more or less sensitive alteration in the nutritional status of patients. In addition, both malnutrition and HIV negatively influence the risk of developing tuberculosis and the outcome of treatment due to deterioration of the immune defenses mediated by $\mathrm{T}$ lymphocytes, hence the association between HIV-TB co-infection and poor nutritional status [16] [17] [18].

Finally, a more favorable outcome was significantly associated with good nutritional status ( $\mathrm{p}<0.001$; OR $=12$, CI 8.0 - 18.9). Indeed, it is widely recognized that nutrition is an important underbody to the immune response. Malnutrition alone or associated with other pathologies (especially tuberculosis) is one of the leading causes of infant mortality in sub-Saharan Africa [4] [19]. Thus, improving the nutritional status of tuberculous malnourished children would be beneficial in improving their prognosis.

\section{Conclusion}

This study assessed the nutritional status of children with tuberculosis and treated in a city in the DR Congo. It appears that a significant proportion of children suffer from underweight. It is therefore imperative that a policy of nutritional supplementation for tuberculous children in DR Congo be developed concomitantly with tuberculosis treatment, especially if they are very young or if they suffer from HIV co-infection.

\section{References}

[1] National Tuberculosis Program (2013) National Guide for the Management of Tuberculosis and Tuberculosis-HIV in Children in DR Congo, Democratic Republic of 
Congo.

[2] World Health Organization (WHO) (2012) Global Tuberculosis Report, 1-28. World Health Organization, Geneva.

[3] Berti, E., Galli, L., Venturini, E., Martini, M. and Chiappini, E. (2014) Tuberculosis in Childhood: A Systematic Review of National and International Guidelines. BMC Infectious Diseases, 14, 53. https://doi.org/10.1186/1471-2334-14-S1-S3

[4] Janagath, D. and Mupere, E. (2012) Childhood Tuberculosis and Malnutrition. IID, 206, 1809-1815. https://doi.org/10.1093/infdis/jis608

[5] UNICEF (2014) The Situation of Children in the World. Janvier, 1-110.

[6] World Health Organization (WHO) (2006) Guidance for National Tuberculosis Programs on the Management of Tuberculosis in Children. World Health Organization, Geneva.

[7] National Tuberculosis Program (2015) National Guide for the Management of Tuberculosis PATI-5, Democratic Republic of Congo.

[8] USAID (2006) Assessment of the Nutritional Situation in Emergencies. www.fantaproject.org

[9] Harries, A.D., Graham, S.M., Mwansambo, C., Kazembe, P., Broadhead, R.L., Maher, D. and Salaniponi, F.M. (2002) Childhood Tuberculosis in Malawi Nationwide Case-Finding and Treatment Outcomes. The International Journal of Tuberculosis and Lung Disease, 6, 424-431.

[10] van Rie, A., Beyers, N., Gie, R.P., Kunneke, M., Donald, L. and Zietsman, P.R. (1999) Childhood Tuberculosis in an Urban Population in South Africa: Burden and Risk Factors. Archives of Disease in Childhood, 80, 433-437. https://doi.org/10.1136/adc.80.5.433

[11] Murray, C.J.L., Stylbo, K. and Rouillon, A. (1990) Tuberculosis in Developing Countries: Burden, Response and Cost. Bulletin of International Union Against Tuberculosis and Lung Disease, 65, 6-24.

[12] Olusoji, J.D., Olusola, A.A., Husseine, A.A.R. and Jaiyesime, O.E. (2015) Trend of Childhood TB Case Notification in Lagos, Nigeria. International Journal of Mycobacteriology, 4, 239-244. https://doi.org/10.1016/j.ijmyco.2015.05.010

[13] Tsai, K.S., Chang, H.L., Dog, S.T., Chen, K.L., Chen, K.H., May, M.H. and Chen, K.T. (2013) Childhood Tuberculosis: Epidemiology, Diagnosis, Treatment and Vaccination. Pediatrics and Neonatology, 54, 295-302.

https://doi.org/10.1016/j.pedneo.2013.01.019

[14] Ministry of Planning (2014) Demographic and Health Survey 2013-2014, Democratic Republic of Congo.

[15] Islam, Q.S., Ahmed, S.M., Islam, M.A., Kamruzzaman, M. and Rifat, M. (2013) Beyond Drugs: Tuberculosis Patients in Bangladesh Need Nutritional Carrier during Convalescence. PHA, 3, 136-140. https://doi.org/10.5588/pha.13.0005

[16] Pawlowski, A., Jansson, M., Sköld, M., Rottenberg, M.E. and Källenius, G. (2012) Tuberculosis and HIV Co-Infection. PLoS Pathogens, 8, e1002464. https://doi.org/10.1371/journal.ppat.1002464

[17] Venturini, E., Turkova, A., Chiappini, E., Galli, L., Martino, M. and Thorne, C. (2014) Tuberculosis and HIV Co-Infection in Children. BMC Infectious Diseases, 14, S5. https://doi.org/10.1186/1471-2334-14-S1-S5

[18] Hoa, N.B., Lauritsen, J.M. and Rieder, H.L. (2013) Changes in Body Weight and Tuberculosis Treatment Outcome in Vietnam. International Journal of Tuberculosis and Lung Disease, 17, 61-66. https://doi.org/10.5588/ijtld.12.0369 
[19] Cegielski, J.P. and McMurray, D.N. (2004) The Relationship Entre Malnutrition and Tuberculosis: Evidence from Studies in Humans and Experimental Animals. International Journal of Tuberculosis and Lung Disease, 8, 286-298.

Submit or recommend next manuscript to OALib Journal and we will provide best service for you:

- Publication frequency: Monthly

- 9 subject areas of science, technology and medicine

- Fair and rigorous peer-review system

- Fast publication process

- Article promotion in various social networking sites (LinkedIn, Facebook, Twitter, etc.)

- Maximum dissemination of your research work

Submit Your Paper Online: Click Here to Submit

Or Contact service@oalib.com 